\title{
Carbazole hydroxylation by the filamentous fungi of the Cunninghamella species
}

\author{
K. Zawadzka ${ }^{1} \cdot$ P. Bernat $^{1} \cdot$ A. Felczak ${ }^{1} \cdot$ K. Lisowska ${ }^{1}$
}

Received: 9 April 2015 / Accepted: 3 August 2015 / Published online: 16 August 2015

(C) The Author(s) 2015. This article is published with open access at Springerlink.com

\begin{abstract}
Nitrogen heterocyclic compounds, especially carbazole, quinolone, and pyridine are common types of environmental pollutants. Carbazole has a toxic influence on living organisms, and the knowledge of its persistence and bioconversion in ecosystems is still not complete. There is an increasing interest in detoxification of hazardous xenobiotics by microorganisms. In this study, the ability of three filamentous fungi of the Cunninghamella species to eliminate carbazole was evaluated. The Cunninghamella elegans IM 1785/21Gp and Cunninghamella echinulata IM 2611 strains efficiently removed carbazole. The IM 1785/21Gp and IM 2611 strains converted 93 and $82 \%$ of the initial concentration of the xenobiotic $\left(200 \mathrm{mg} \mathrm{L}^{-1}\right)$ after $120 \mathrm{~h}$ incubation. 2Hydroxycarbazole was for the first time identified as a carbazole metabolite formed by the filamentous fungi of the Cunninghamella species. There was no increase in the toxicity of the postculture extracts toward Artemia franciscana. Moreover, we showed an influence of carbazole on the phospholipid composition of the cells of the tested filamentous fungi, which indicated its harmful effect on the fungal cell membrane. The most significant modification of phospholipid levels after the cultivation of filamentous fungi with the addition of carbazole was showed for IM 1785/21Gp strain.
\end{abstract}

Keywords Carbazole $\cdot$ Degradation $\cdot$ Phospholipids · $\mathrm{N}$-heterocycles $\cdot$ Detoxification

Responsible editor: Robert Duran

K. Lisowska

katalis@biol.uni.lodz.pl

1 Department of Industrial Microbiology and Biotechnology, Faculty of Biology and Environmental Protection, University of Lodz, 12/16 Banacha Street, 90-237 Lodz, Poland

\section{Introduction}

Nitrogen heterocyclic aromatic compounds are one of the most important classes of the environmental pollutants, which have been detected in air, soil, and water samples (Singh et al. 2011a, b; Xu et al. 2006). Besides quinolone and pyridine, carbazole is a common contaminant generated from petrochemical and coking industries (Zhao et al. 2011b). This compound contaminates shale oil, crude oil, coal tar, and petroleum distillates (Castorena et al. 2006). Carbazole and its derivatives are used for the production of dyes, plastics, insecticides, and medicines (Loh and Yu 2000; Lobastova et al. 2004).

The mutagenic, carcinogenic, and toxic activities of carbazole have been documented (Jha and Bharti 2002; Jha et al. 2002; Mumbo et al. 2015). Its mutagenic potential toward Swiss albino mice was reveled in many studies. Carbazole induced dominant lethal mutation and formation of sperm head abnormalities in male germ cells of mice (Jha and Bharti 2002). Moreover, Jha et al. (2002) observed a clastogenicity effect of carbazole in the concentrations of 150 and $200 \mathrm{mg} / \mathrm{kg}$ body weight in Swiss albino mice. These concentrations of the xenobiotic caused a decrease in the mitotic index and an increase in the chromosomal aberration frequency in bone marrow cells (Jha et al. 2002). Mumbo et al. evidenced dioxine-like toxicity of carbazole in soil (Mumbo et al. 2015). According to the recommendation of the European Trade Union Institute (2009), carbazole was classified as a possible carcinogen to human (B2 group) and the Agency for Toxic Substances and Disease Registry (2015) included it in the priority list of hazardous substances.

The hydrophobic character of the xenobiotic promotes its accumulation in sediment, which may result in its long lasting harmful influence on aquatic organisms (Singh et al. 2011b; Zhao et al. 2011; Loh and Yu 2000). Microbial degradation 
can be an efficient method for the conversion of dangerous xenobiotics; therefore, a search for microorganisms capable of their utilization and finding the mechanisms of these processes are very important (Xu et al. 2006). Literature data point to many carbazole-degrading bacterial strains. Ouchiyama et al. (1993) isolated two bacterial strains of Pseudomonas sp., which have an ability to use carbazole as a sole source of carbon, nitrogen, and energy. The authors identified the main products of bacterial metabolism of carbazole and proposed a pathway of its biodegradation (Ouchiyama et al. 1993). The results of subsequent studies confirmed the pathway of bacterial degradation of carbazole, which had been suggested by Ouchiyama (Nam et al. 2012; Kirimura et al. 1999; Seo et al 2006). Carbazole 1,9a-dioxygenase (CARDO) is a key factor of bacterial metabolism of the xenobiotic. The first step of the catalysis by this enzyme is introducing two hydroxyl groups to the structure of carbazole and cleavage of its aromatic ring followed by a formation of 2'-aminobiphenyl-2,3-diol (Xu et al. 2006). The pathway of carbazole degradation by different bacteria and its molecular basis has been well documented. However, there are a few information about degradation of carbazole and its derivatives by filamentous fungi (Yang and Davis 1992, Lobastova at al. 2004; Parshikov et al. 2012). Filamentous fungi from the genus Cunninghamella demonstrated the capability of degrading a broad spectrum of xenobiotics (Lisowska and Długoński 2003; Bernat et al. 2013; Asha and Vidyavathi 2009; Parshikov et al. 2012).

The contact of microorganism cells with toxic and harmful substances can result in the perturbation of their structure and functionality. For this reason, bacteria and fungi have an ability to adapt and survive in the presence of xenobiotics (Dercová et al. 2004). Microorganisms can change the lipid molecular species proportion in response to a toxic compound. The use of liquid chromatography and tandem mass spectrometry (LC-MS/MS) techniques allows analyzing the lipid profile and its modification under the influence of stress factors (Welti et al. 2002).

The aim of this paper was to investigate the ability of carbazole degradation by three filamentous fungi from the genus Cunninghamella (C. elegans IM 1785/21Gp, C. echinulata IM 2611, C. elegans DSM 8217). We also analyzed the metabolites of carbazole produced by the tested microorganisms and their toxicity toward Artemia franciscana. Moreover, the modifications in the phospholipid profile of the filamentous fungi in response to carbazole were examined.

\section{Materials and methods}

\section{Chemicals}

Carbazole, 2-hydroxycarbazole, 4-hydroxycarbazole, and phenylcarbazole were purchased from Sigma. Other reagents were high purity grade chemicals obtained from $\mathrm{POCH}$ (Poland) and JT Baker (USA).

\section{Microorganisms and growth conditions}

The Cunninghamella elegans IM 1785/21Gp and Cunninghamella echinulata IM 2611 came from the collection of the Department of Industrial Microbiology and Biotechnology, University of Lodz (Poland). C. elegans DSM 8217 was purchased from DSMZ collection (Germany). Spores of tested filamentous fungi from 7 day-old cultures were employed for the preparation of precultures in Sabouraud dextrose broth liquid medium (Difco, USA) supplemented with $2 \%$ glucose. Microorganisms were cultured for $24 \mathrm{~h}$ at $28{ }^{\circ} \mathrm{C}$ on a rotary shaker (145 rpm) in $100 \mathrm{~mL}$ Erlenmeyer flasks. The precultures were resuspended in $40 \mathrm{~mL}$ fresh Sabouraud medium with $2 \%$ glucose and cultivated for subsequent $24 \mathrm{~h}$. The carbazole stock was prepared in a mixture of DMSO:Tween 80 (1:2). Carbazole elimination, dry weight, and lipid profile modification were examined in Czapek-Dox liquid medium, composed of $3 \mathrm{~g} \mathrm{~L}^{-1} \mathrm{NaNO}_{3} ; 1 \mathrm{~g} \mathrm{~L}{ }^{-1} \mathrm{KH}_{2} \mathrm{PO}_{4} ; 0.5 \mathrm{~g} \mathrm{~L}^{-1} \mathrm{KCl}$; $0.5 \mathrm{~g} \mathrm{~L}^{-1} \mathrm{MgSO}_{4} \times 7 \mathrm{H}_{2} \mathrm{O} ; 0.01 \mathrm{~g} \mathrm{~L}^{-1} \mathrm{FeSO}_{4} \times 7 \quad \mathrm{H}_{2} \mathrm{O}$; $40 \mathrm{~g} \mathrm{~L}^{-1}$ glucose. Erlenmeyer flasks $(100 \mathrm{~mL})$ containing $18 \mathrm{~mL}$ Czapek-Dox medium were supplemented with $200 \mathrm{mg} \mathrm{L}^{-1}$ carbazole and inoculated with $2 \mathrm{~mL}$ of previously prepared fungal biomass. Biotic controls were performed without the addition of carbazole. The cultures were carried out on a rotary shaker at $28{ }^{\circ} \mathrm{C}$ for 5 days. Each measured time point was prepared in three independent repetitions. For dry weight determination, the mycelium was separated by filtration, washed with distilled water, and dried at $100{ }^{\circ} \mathrm{C}$ to a constant weight.

\section{Carbazole extraction and GC-MS-analysis}

After incubation, the filamentous fungi cultures were disintegrated for 5 min using Mixer Mill MM400 (Retsch, Germany) and $1 \mathrm{M} \mathrm{HCl}$ was added to $\mathrm{pH}$ 3. Carbazole and its metabolites were extracted with ethyl acetate $(1: 1, v / v)$. Ethyl acetate extracts were dehydrated using anhydrous sodium sulfate and then evaporated to dryness at $43{ }^{\circ} \mathrm{C}$. After evaporation, each sample was resuspended in $2 \mathrm{~mL}$ ethyl acetate and analyzed by GC-MS. Phenylcarbazole was used as an internal standard in the quantitative analysis. The Agilent Technologies 7890A Gas Chromatography system equipped with a methyl polysiloxane HP 5MS column $(30 \mathrm{~m} \times$ $0.25 \mathrm{~mm}$ ) and a $5975 \mathrm{C}$ Triple-Axis Detector (Agilent Technologies, USA) was used. The analysis was carried out using helium as a gas carrier at $1.2 \mathrm{~mL} \mathrm{~min}^{-1}$. In quantitative and qualitative methods, the oven temperature was set in the 
ranges of $100-300$ and $80-300^{\circ} \mathrm{C}$, respectively. For the quantitative analysis, the ion at $167 \mathrm{~m} / \mathrm{z}$ was used. The qualitative analyses were carried out at the mass range $100-400 \mathrm{~m} / \mathrm{z}$.

\section{Toxicity study}

Toxicity of postculture extracts was evaluated using the Artoxkit M test (Microbiotests, Inc., Mariakerke-Gent, Belgium). Extracts of tested filamentous fungi incubated with carbazole and abiotic control were prepared according to $\mathrm{p}$. 2.2. and 2.3. Brine shrimp cysts of $A$. franciscana were transferred to saline water in petri dishes and incubated for $48 \mathrm{~h}$ with an exposure to a light source at 3000 lux. The larvae of A. franciscana were incubated with postculture extracts or carbazole dissolved in DMSO. Toxicity of carbazole and its metabolites was calculated as a percentage of larvae that were not mobile after $48 \mathrm{~h}$ incubation.

\section{Lipid determination by HPLC-MS/MS analysis}

Lipid profile determination was prepared according to Bernat et al. 2014 using the HPLC-MS/MS techniques. The mycelia of all tested fungi in the stationary phase of growth were separated from medium and crushed with $10 \mathrm{~mL} \mathrm{MeOH}$ using a Mixer Mill MM400 (Retsch, Germany). The suspension was centrifuged at $6000 \mathrm{rpm}$ for $3 \mathrm{~min}$ at $4{ }^{\circ} \mathrm{C}$. The supernatant was isolated from biomass and vortexed for $2 \mathrm{~min}$ with an addition of $20 \mathrm{~mL}$ chloroform. Collected organic phases were anhydrated with sodium sulfate and evaporated to dryness. Extracts were redisolved in $500 \mu \mathrm{L}$ of chloroform and suspended 25-fold in MeOH. An Agilent 1200 HPLC system and a 3200 Q-Trap mass spectrometer with ESI source were used for the analysis of polar lipids. A Synergi ${ }^{\mathrm{TM}}$ Max-RP capillary column $(50 \mathrm{~mm} \times 2 \mathrm{~mm}, 4 \mu \mathrm{m}$ particle size, $80 \AA$ pore size, Phenomenex, Torrance, USA) was used for the reversed-phase chromatographic analysis. The temperature of the column was $40^{\circ} \mathrm{C}$. The injection volume was $5 \mu \mathrm{L}$. The $5 \mathrm{mM}$ ammonium formate in water (A) and $5 \mathrm{mM}$ ammonium formate in $\mathrm{MeOH}(\mathrm{B})$ were used as mobile phases. The solvent gradient with a constant flow rate of $600 \mu \mathrm{L} \mathrm{min}{ }^{-1}$ was started at $60 \%$ of eluent $\mathrm{B}$ and maintained to $0.5 \mathrm{~min} ; 100 \%$ of eluent $\mathrm{B}$ in $1.5 \mathrm{~min}$ and maintained to $6.5 \mathrm{~min}$; and returned to the initial conditions in $8.1 \mathrm{~min}$ and maintained till $10 \mathrm{~min}$ for the stabilization of the column. The parameters of the ESI ion source were set as IS: $-4500 \mathrm{~V}$, CUR:25, GS1:50, GS2:60, and TEM:600 ${ }^{\circ} \mathrm{C}$. The Analyst $^{\mathrm{TM}}$ version 1.5.1 software (AB Sciex, Framingham, MA, USA) was used in quantitative and qualitative analyses.

\section{Statistical analysis}

All obtained results were presented as mean \pm standard deviation (SD). The one-way analysis of variance (ANOVA) with $p$ value $<0.05$ was used for the evaluation of statistical significance.

\section{Results and discussion}

\section{Growth of the Cunninghamella strains with carbazole}

Many Cunninghamella strains are able to metabolize different hazardous pollutants, including phenanthrene, fluorine, 1methylnaphthalene, benzo[e]pyrene, malachite green, and 6nitrochrysene. Moreover, these microorganisms can lead to the formation of heteroatom oxidized, N- or O-demethylated and hydroxylated metabolites (Lisowska and Długoński 2003; Črešnar and Petrič 2011; Zhang et al. 1996). Data concerning the pathway of carbazole bioconversion by filamentous fungi are still very limited in contrast to the information documenting the degradation ability of different bacteria (Zhao et al. 2011; Loh and Yu 2000; Larentis et al. 2011; Yoon et al. 2002). For this reasons we studied ability to carbazole degradation by Cunninghamella strains.

In the present study, the influence of carbazole at the concentration of $200 \mathrm{mg} \mathrm{L}^{-1}$ on the growth of the filamentous fungi C. elegans IM 1785/21Gp, C. echinulata IM 2611, and C. elegans DSM 8217 was investigated (Fig. 1). All tested microorganisms showed high tolerance toward high concentrations of carbazole. The xenobiotic exhibited the highest toxicity toward the IM $1785 / 21 \mathrm{Gp}$ strain (Fig. 1a). In the cultures of this fungus, the $30 \%$ limitation of growth compared with control samples without carbazole was noted after $120 \mathrm{~h}$ incubation. In the case of the DSM 8217 strain, an inconsiderable inhibition of growth was observed (Fig. 1c). Addition of carbazole to culture IM 2611 did not wield toxicity influence to growth of biomass synthesis (Fig. 1b).

\section{Quantitative and qualitative GC-MS analysis of carbazole elimination}

Samples for quantitative and qualitative analyses were collected after $24,48,72,96$, and $120 \mathrm{~h}$ cultivation of the filamentous fungi with carbazole. Reference samples were biotic and abiotic controls incubated for the same time periods. The ability of all the three Cunninghamella strains to utilize carbazole was demonstrated. The dynamics of carbazole elimination by the tested filamentous fungi is shown in Fig. 2. The fungus C. elegans IM $1785 / 21 \mathrm{Gp}$ was the most effective and eliminated almost completely $200 \mathrm{mg} \mathrm{L}^{-1}$ of carbazole within $120 \mathrm{~h}$ of incubation. High correlation between reduction of IM 1785/21Gp strain growth and its ability to carbazole elimination confirmed toxic influence of tested xenobiotic. C. echinulata IM 2611 also showed high effectiveness in removing the tested compound. The lowest capacity of carbazole biodegradation was reported for the C. elegans DSM 
Fig. 1 Growth of C. elegans IM 1785/21Gp (a), C. echinulata IM 2611 (b), and C. elegans DSM 8217 (c) in the presence of carbazole at the concentration $200 \mathrm{mg} \mathrm{L}^{-1}$ on Czapek-Dox liquid medium, during $120 \mathrm{~h}$ of incubation. Each result represents an average and SD was taken from $n \geq 3$
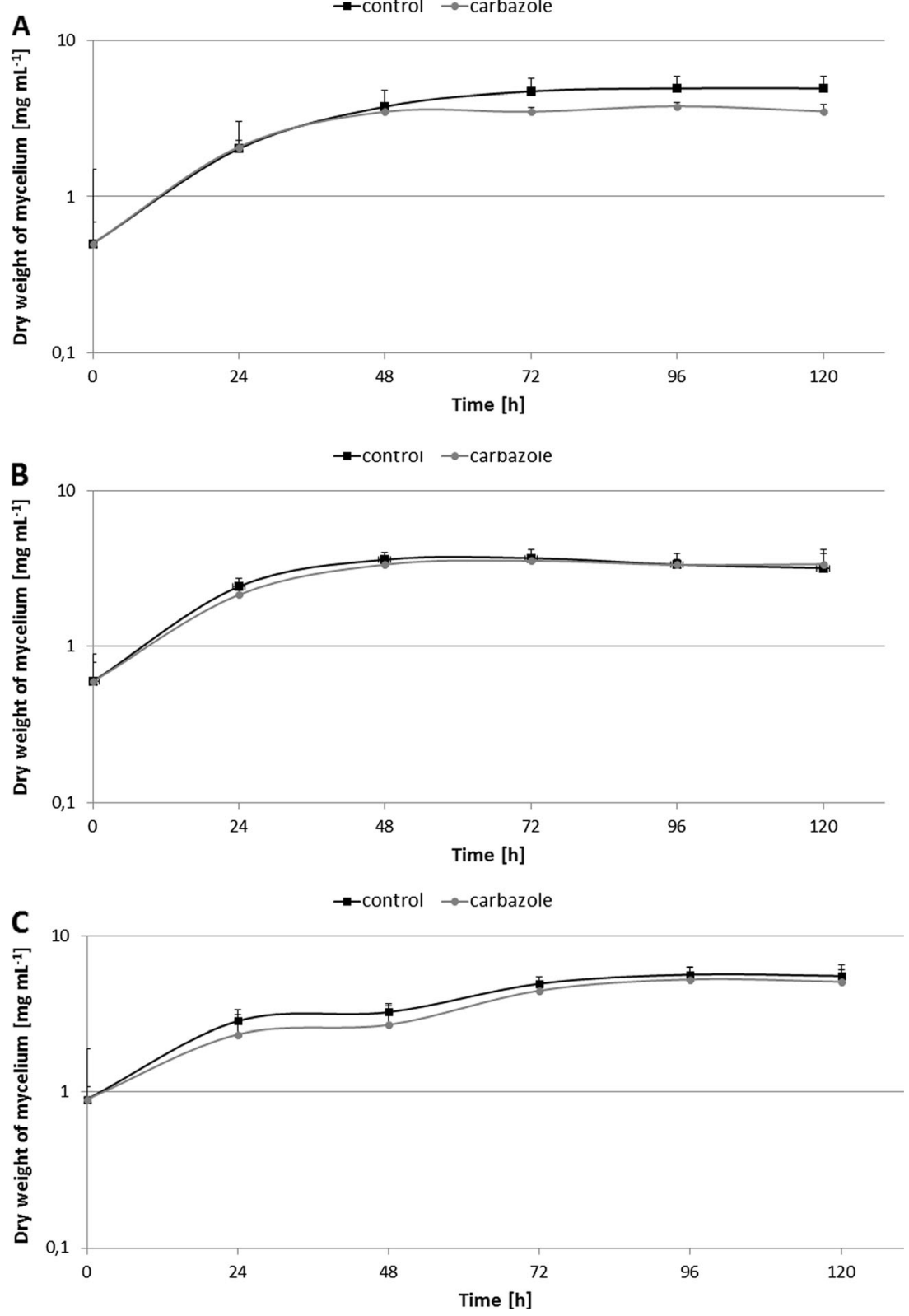

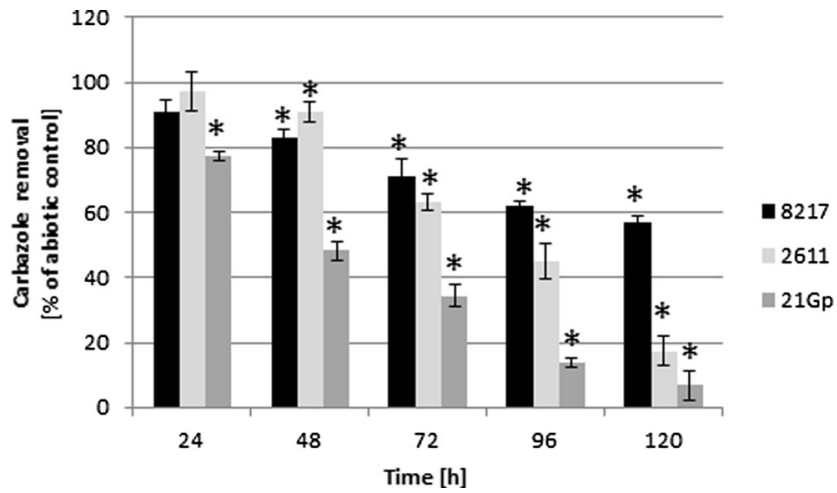

Fig. 2 Elimination of carbazole $\left(200 \mathrm{mg} \mathrm{L}^{-1}\right)$ by tested microorganisms. Each result represents an average ( $n \geq 3$ collected from three independent experiments). Statistical analysis was done using the Student's test with ${ }^{*} p<0.005$
8217 strain. After $120 \mathrm{~h}$ cultivation, the filamentous fungi IM $1785 / 21 \mathrm{Gp}$ and IM 2611 with the addition of carbazole removed 93.1 and $82.6 \%$ of the initial concentration of the xenobiotic, while the DSM 8217 strain eliminated only $43.1 \%$ of carbazole.

The examples of the chromatogram and mass spectra of carbazole products formed by C. elegans IM1785/21Gp are shown in Figs. $3 \mathrm{a}$ and 4a. The three carbazole derivatives were detected by qualitative and quantitative GC-MS methods. Three hydroxylated metabolites of carbazole with the retention times $\left(R_{\mathrm{t}}\right) 11.2 \mathrm{~min}$ (metabolite 1), 11.49 min (metabolite 2 ), and 11.54 min (metabolite 3 ) min were detected and identified by a mass fragmentation pattern compared with NIST Standard Reference Database in the extracts of the IM 1785/ 
Fig. 3 GC-MS chromatogram showing the carbazole derivatives with the retention times $\left(R_{\mathrm{t}}\right)$ $11.2 \mathrm{~min}$ (metabolite 1),

11.49 min (metabolite 2), and $11.54 \mathrm{~min}$ (metabolite 3 ) formed by IM $1785 / 21 \mathrm{Gp}$ strain after $120 \mathrm{~h}$ incubation (a) and standard of 2-hydroksycarbazole (b)
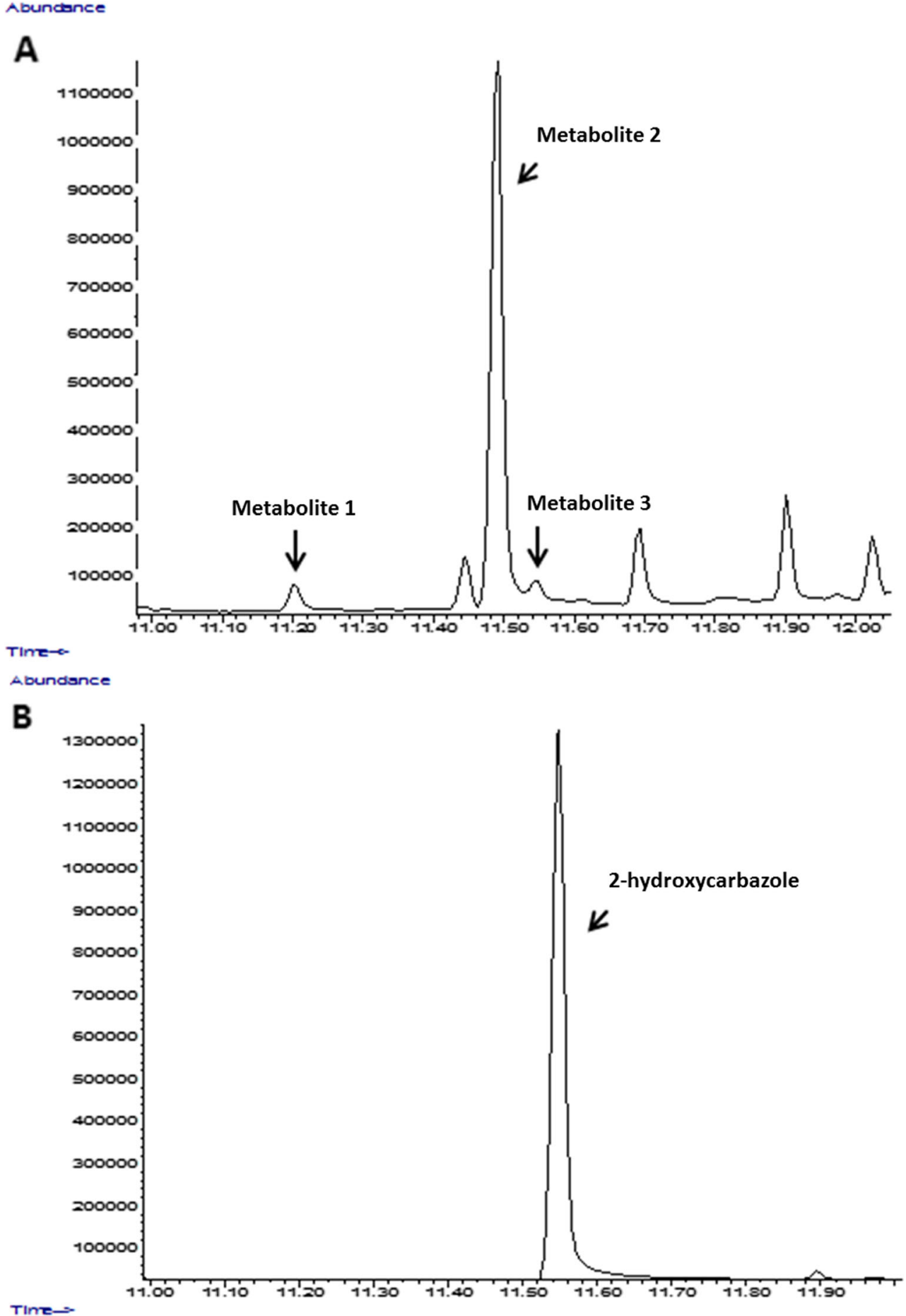

$21 \mathrm{Gp}$ and IM 2611 strains. In the case of the DSM 8217 strain, only metabolite 2 was detected. The monohydroxylated metabolites of carbazole were identified on the basis of a molecular ion at $183 \mathrm{~m} / \mathrm{z}$. Based on the comparison of the obtained chromatograms and mass spectra of carbazole metabolites produced by the tested microorganisms and available hydroxycarbazole standards, metabolite 3 was recognized as 2-hydroxycarbazole (Figs. 3b and 4b). For the first time, we identified 2-hydroxycarbazol as a product of carbazole biotransformation by the filamentous fungi of the Cunninghamella. In the case of metabolite $1\left(R_{\mathrm{t}}=11.2 \mathrm{~min}\right)$ and metabolite $2\left(R_{\mathrm{t}}=11.49 \mathrm{~min}\right)$, oxidation of carbazole in positions 2 and 4 was excluded, because the retention times of 2-hydroxycarbazole and 4-hydroxycarbazol were 11.54 and $11.41 \mathrm{~min}$, respectively. Based on the comparison of our results with mass spectra and retention times available in 
Fig. 4 Mass spectrum of the carbazole derivatives with the retention times $\left(R_{\mathrm{t}}\right) 11.54 \mathrm{~min}$ (metabolite 3 ) formed by IM $1785 / 21 \mathrm{Gp}$ strain after $120 \mathrm{~h}$ incubation (a) and standard of 2-hydroksycarbazole (b)
Abundance

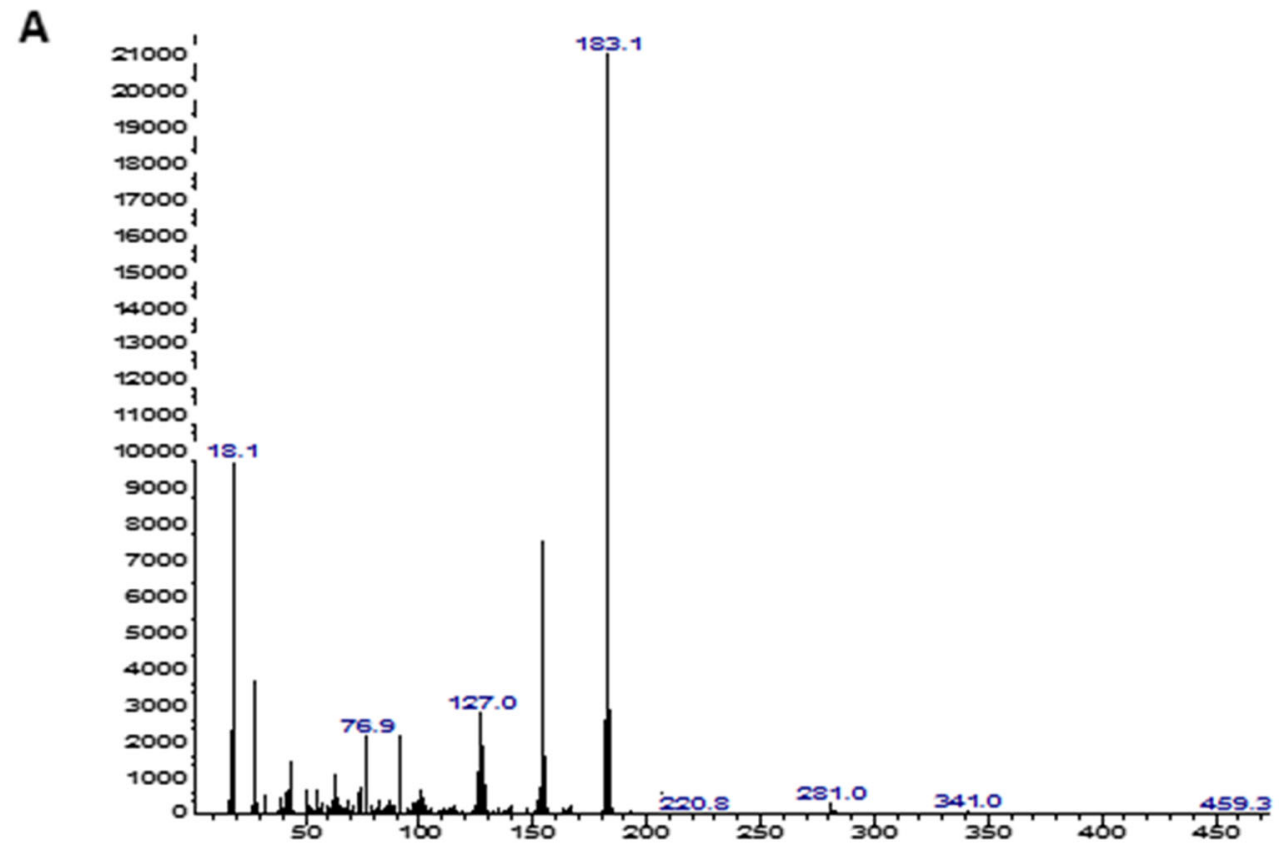

$m x=$

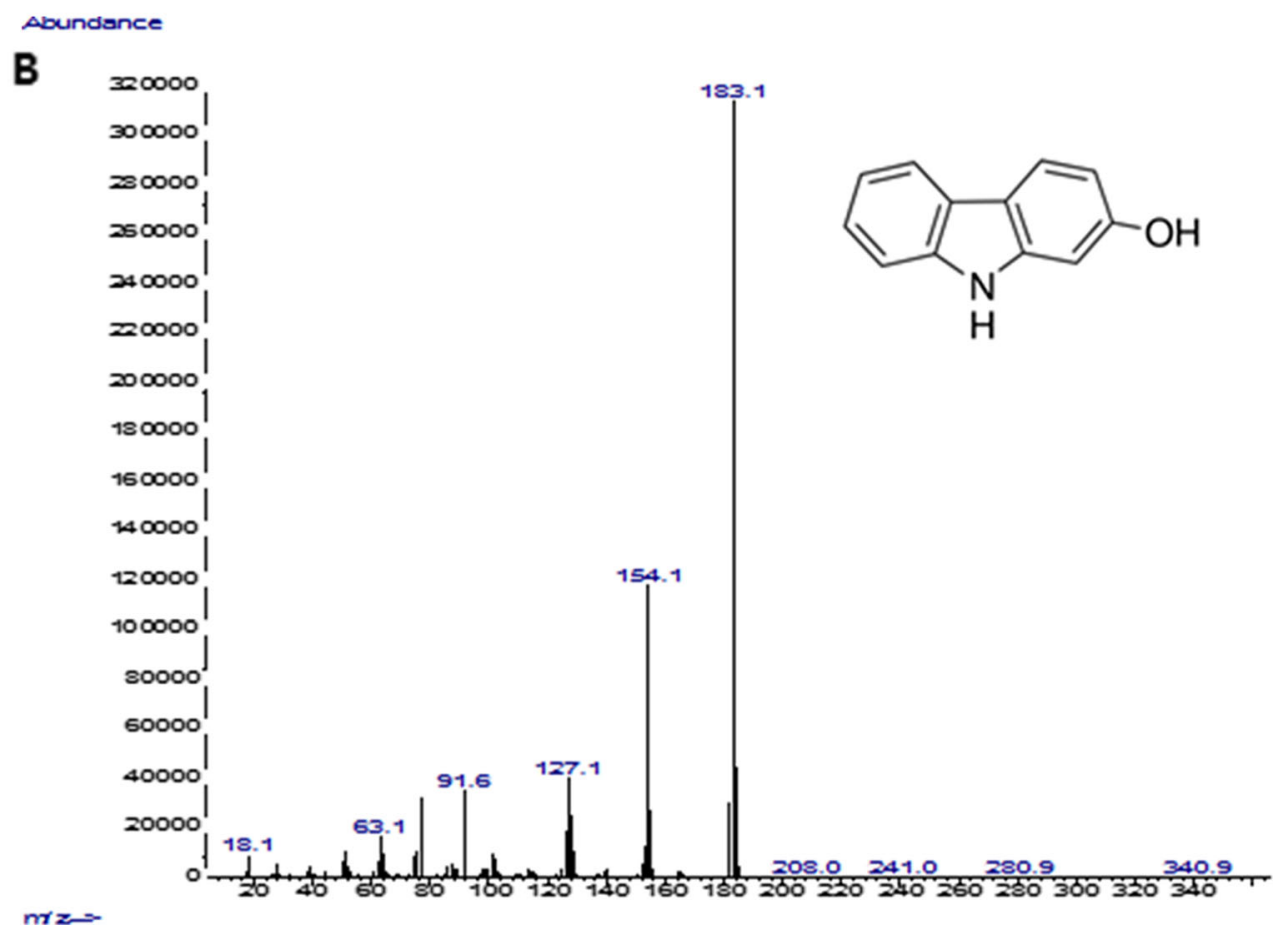

literature (Yang and Davis 1992; Lobastova et al. 2004), it can be suggested that metabolite 2 is a hydroxylated product of carbazole in position 3. In the case of genus Cunninghamella, hydroxylated products were noted during the conversion of $N$ methylcarbazole. The fungus C. echinulata ATCC 9244 was shown to transform $\mathrm{N}$-methylcarbazole to carbazole, $\mathrm{N}$ hydroxymethylcarbazole, 3-hydroxycarbazole, and $N$-hydroxy- $N$-methylcarbazole (Yang and Davis 1992). The strain of $C$. elegans converted carbazole to 3-hydroxycarbazole (Lobastova et al. 2004; Parshikov et al. 2012). Lobastova et al. (2004) showed biotransformation of carbazole by Aspergillus flavus VKM F-1024 and detected three monohydroxylated metabolites, which were identified as 1-, 2-, 3-hydroxycarbazole. In a culture pre-incubated with 1benzylindol, mono- and dihydroxylated derivatives of carbazole were identified. 2-Hydroxycarbazole was detected solely 
as an intermediate of carbazole transformation by A. flavus (Lobastova et al. 2004).

\section{Toxicity assay of carbazole metabolites}

Carbazole is a well-known environmental pollutant which has a negative influence on different organisms. Sverdrup et al. (2003) showed high toxicity of carbazole toward Trifolium pretense, Lolium perenne, and Sinepsis alba. The $20 \%$ reduction of seeding fresh weight (EC20-value) was evaluated in the range of 36-290 $\mathrm{mg} \mathrm{kg}^{-1}$ (Sverdrup et al. 2003). The determination of the carbazole influence on Danio rerio showed its high hazardous potential. Carbazole was one of the most toxic NSO-heterocycylic compounds with LC50 $1.07 \mathrm{mg} \mathrm{L}^{-1}$ (Peddinghaus et al. 2012). EC50-values of carbazole for Daphnia and Vibrio fisheri were 3.4 and $11.57 \mathrm{mg} \mathrm{L}^{-1}$, respectively (Blum et al. 2011). Moreover, the dioxin-like toxicity of carbazole was documented. Mumbo et al. (2015) showed the affinity of carbazole to the aryl hydrocarbon receptor (AHR). Nebert and Dalton (2006) supposed that activation of AHR by three polychlorinated biphenyl can result in the induction of cytochrome P450.

Metabolites of the hazardous pollutant formed during microbial degradation can be more harmful to living organisms than the parent compound (Bernat et al. 2013). Therefore, we analyzed the toxicity of the postculture extracts of the studied fungal strains. Artoxkit $M$ was used for assessing the mortality of A. franciscana after the exposure to postculture extracts. The $48 \mathrm{~h}$ LC50 value obtained for pure carbazole was $20.83 \pm$ $3.82 \mathrm{mg} \mathrm{L}^{-1}$. The $48 \mathrm{~h}$ LC50 values received for postculture extracts were similar to the value reached for carbazole. Metabolites formed by the tested fungi did not show higher toxicity than parent substrates. Similar results were obtained by Słaba et al. (2013) who did not observe an increase in the toxicity of alachlor and its derivatives. The authors suggested that alachlor degradation by Paecilomyces marquandii did not lead to the complete detoxification of the xenobiotic, but metabolites produced by $P$. marquandii can be more easily metabolized by other soil microorganisms.

\section{Changes in the fungi phospholipid composition in response to carbazole}

The phospholipid (PL) profiles of the tested filamentous fungi were evaluated according to Bernat et al. (2014). The 46 species of PLs including phosphatidic acid (PA), phosphatidylethanolamine (PE), phosphatidylserine (PS), phosphatidylcholine (PC), and phosphatidylinositol (PI) were analyzed using the LC-MS/MS techniques. Recently, the modification of the microorganism's lipid profile in response to the toxic compound has been shown (Dercová et al. 2004; Bernat et al. 2014; Xia and Yuan 2009). The dominant type of PLs in each filamentous fungus was PC and it comprised $48-59 \%$ of the total cell PLs in samples without the addition of carbazole (Table 1). Our results are similar to those obtained by Bernat et al. (2013) who described the induction of oxidative stress and modification of the lipid profile of the C. elegans membrane by tributyltin. The values of 27-37, 6-12, 1.6-4.5, and 2-7 \% were achieved for PE, PS, PI, and PA, respectively. Significant modification of PE contents were noted for IM 1785/21Gp and IM 2611 strains incubated with carbazole. The 6.3 and $4.7 \%$ decrease in PE levels were observed in cells of IM 1785/21Gp and IM 2611 strains, respectively. The PC/PE ratio decides about the integrity of the membrane and the functioning of cells (Welti et al. 2002; Bernat et al. 2014). The differences in the $\mathrm{PC} / \mathrm{PE}$ ratios after the incubation of the fungi with carbazole were determined. For the 1785/ $21 \mathrm{Gp}$ and IM 2611 strains, the PC/PE ratio increased by 28.6 and $18.9 \%$, respectively. The more significant enhancement of the $\mathrm{PC} / \mathrm{PE}$ ratio and $30 \%$ reduction in growth were noted in the cultures of the IM $1785 / 21 \mathrm{Gp}$, which can suggest that among the three tested strains, IM $1785 / 21 \mathrm{Gp}$ is the most sensitive to carbazole. Moreover, there was a significant decline in the PS level observed in IM 1785/21Gp and IM 2611 cultures, which could have been caused by use of PS as a
Table 1 The phospholipid composition [\%] of the tested microorganisms from the stationary phase incubated with or without carbazole

\begin{tabular}{|c|c|c|c|c|c|c|}
\hline \multirow[t]{2}{*}{ Lipid species } & \multicolumn{2}{|c|}{ IM 1785/21Gp } & \multicolumn{2}{|l|}{ IM 2611} & \multicolumn{2}{|l|}{ DSM 8217} \\
\hline & Control & Carbazole & Control & Carbazole & Control & Carbazole \\
\hline PA & $4.63 \pm 0.62$ & $7.22 \pm 1.83^{*}$ & $2.29 \pm 0.27$ & $3.26 \pm 1.40$ & $1.99 \pm 0.59$ & $3.10 \pm 0.97$ \\
\hline PE & $33.99 \pm 1.25$ & $27.69 \pm 3.47^{*}$ & $27.29 \pm 0.41$ & $22.59 \pm 1.94 *$ & $37.84 \pm 1.74$ & $35.98 \pm 4.37$ \\
\hline PS & $8.42 \pm 1.40$ & $6.26 \pm 0.68^{*}$ & $9.84 \pm 0.79$ & $11.47 \pm 0.29 *$ & $12.02 \pm 1.11$ & $11.93 \pm 2.52$ \\
\hline PC & $48.88 \pm 3.24$ & $54.29 \pm 4.12$ & $58.50 \pm 1.55$ & $59.68 \pm 0.77$ & $46.49 \pm 0.64$ & $48.99 \pm 5.36$ \\
\hline PI & $4.01 \pm 0.39$ & $4.54 \pm 0.52$ & $2.05 \pm 0.07$ & $3.14 \pm 0.10^{*}$ & $1.64 \pm 0.39$ & $2.56 \pm 0.73$ \\
\hline $\mathrm{PC} / \mathrm{PE}$ & 1.44 & 1.96 & 2.14 & 2.64 & 1.23 & 1.36 \\
\hline
\end{tabular}

Each result represents an average and SD taken from $n \geq 3$. Statistical analysis was done using the Student's test with $* p<0.005$ 
precursor in the PE and PC synthesis (Xia and Yuan 2009). Interestingly, an almost 1.5-fold significant increase in the PA level was noted in IM 1785/21 Gp cells exposed to carbazole compared to control samples. PA is considered to be a signal lipid in response to many abiotic and biotic stress factors. An increase in the PA content in plants after the contact with salts, heavy metals, $\mathrm{H}_{2} \mathrm{O}_{2}$, and different pathogens was described (Testerink and Munnik 2005; Darwish et al. 2009). The significant growth of signal lipid level in IM $1785 / 21 \mathrm{Gp}$ cells was correlated with growth inhibition of this strain. Similar results were obtained for $C$. elegans incubated with tributyltin. It can be suggested that the growth of the PA level could have caused the decline in the level of PE, which can be used as a substrate for PA synthesis (Bernat et al. 2014). The significant increase of PI level was observed for IM 261 strain. PI play many important roles in eukaryotic cells. PI and its derivatives can stabilize cell membrane. Moreover, literature data suggest that PI can be involved in response of microorganisms to growth conditions (Gardocki et al. 2005). Increase of PI level in IM 2611 cells can be connected with high tolerance of this strain to tested xenobiotic. For the DSM 8217 strains, modification of phospholipid profile was insignificant what indicate that carbazole is the least toxic for this strain.

\section{Conclusions}

In the present study, the ability of the filamentous fungi C. elegans IM 1785/21Gp, C. echinulata IM 2611, and C. elegans DSM 8217 to utilize carbazole was determined. The GC-MS analysis of postculture extracts resulted in the identification of three carbazole derivatives. The pathway of carbazole degradation by the filamentous fungi of the Cunninghamella species involved the oxidation reaction. All tested microorganisms showed a capability of xenobiotic elimination. The IM 1785/21 Gp and IM 2611 strains appeared to be very effective and produced three monohydroxylated derivatives of carbazole. In the cultures of these strains, about $90 \%$ loss of the substrate was noted. DSM 8217 strain utilized $40 \%$ of carbazole and formed one hydroxylated metabolite. 2Hydroxycarbazole was identified for the first time as a carbazole metabolite formed by the filamentous fungi of the Cunninghamella species. Toxicity of carbazole and its metabolites toward A. franciscana was assessed. An increase in the mortality of larvae after the exposure to postculture extracts was not observed. Moreover, the influence of carbazole on the phospholipid profile of filamentous fungi was evaluated for the first time. The changes in the phospholipid levels after the exposure to carbazole suggested its highest toxicity to the IM $1785 / 21 \mathrm{Gp}$ strain and less harmful activity toward the DSM 8217 strain. The mechanism of the carbazole influence on the changes in the membrane phospholipid composition will be the subject of study in the future.
Acknowledgments This study was supported by the National Centre for Science, Poland (project no. DEC-2013/09/N/NZ9/01668).

Open Access This article is distributed under the terms of the Creative Commons Attribution 4.0 International License (http:// creativecommons.org/licenses/by/4.0/), which permits unrestricted use, distribution, and reproduction in any medium, provided you give appropriate credit to the original author(s) and the source, provide a link to the Creative Commons license, and indicate if changes were made.

\section{References}

Asha S, Vidyavathi M (2009) Cunninghamella — a microbial model for drug metabolism studies - a review. Biotechnol Adv 27:16-29

Bernat P, Szewczyk R, Krupinski M, Długonski J (2013) Butyltins degradation by Cunninghamella elegans and Cochliobolus lunatus coculture. J Hazard Mater 246-247:277-282

Bernat P, Gajewska E, Szewczyk R, Słaba M, Długoński J (2014) Tributyltin (TBT) induces oxidative stress and modifies lipid profile in the filamentous fungus Cunninghamella elegans. Environ Sci Pollut Res 21(6):4228-35

Blum P, Sagner A, Tiehm A, Martus P, Wendel T, Grathwohl P (2011) Importance of heterocyclic aromatic compounds in monitored natural attenuation for coal tar contaminated aquifers: a review. J Contam Hydrol 126:181-194

Castorena G, Mugica V, Le Borgne S, Acun ME, Bustos-Jaimes I, Aburto J (2006) Carbazole biodegradation in gas oil/water biphasic media by a new isolated bacterium Burkholderia sp. strain IMP5GC. J Appl Microbiol 100:739-745

Črešnar B, Petrič Š (2011) Cytochrome P450 enzymes in the fungal kingdom. Biochim Biophys Acta 1814:29-35

Darwish E, Testerink C, Khalil M, El-Shihy O, Munnik T (2009) Phospholipid signaling responses in salt-stressed rice leaves. Plan and Cell Physiol 50(5):986-997

Dercová K, Čertík M, Malová A, Sejáková Z (2004) Effect of chlorophenols on the membrane lipids of bacterial cells. Int Biodeterioration Biodegrad 54:251-254

Gardocki ME, Jani N, Lopes JM (2005) Phosphatidylinositol biosynthesis: biochemistry and regulation. Biochim Biophys Acta 1735:89100

Jha AM, Bharti MK (2002) Mutagenic profiles of carbazole in the male germ cells of Swiss albino mice. Mutat Res 500(1-2):97-101

Jha AM, Singh AC, Bharti MK (2002) Clastogenicity of carbazole in mouse bone marrow cells in vivo. Mutat Res 521:11-17

Kirimura K, Nakagawa H, Tsuji K, Matsuda K, Kurane R, Usami S (1999) Selective and continuous degradation of carbazole contained in petroleum oil by resting cells of Sphingomonas sp. CDH-7, Biosci Biotechnol Biochem 63(9):1563-1568

Larentis AL, Sampaio HCC, Carneiro CC, Martins OB, Alves TLM (2011) Evaluation of growth, carbazole biodegradation and anthranilic acid production by Pseudomonas stutzeri. Braz J Chem Eng 28(1):37-44

Lisowska K, Długoński J (2003) Concurrent corticosteroid and phenanthrene transformation by filamentous fungus Cunninghamella elegans. J Steroid Biochem Mol Biol 85:63-69

Lobastova TG, Sukhodolskaya GV, Nikolayeva VM, Baskunov BP, Turchin KF, Donova MV (2004) Hydroxylation of carbazoles by Aspergillus flavus VKM F-1024. FEMS Microbiol Lett 235:51-56

Loh K-C, Yu Y-G (2000) Kinetics of carbazole degradation by Pseudomonas putida in presence of sodium salicylate. Wat Res 34(17):4131-4138

Mumbo J, Henkelmann B, Abdelaziz A, Pfister G, Nguyen N, Schroll R, Munch JC, Schramm K-W (2015) Persistence and dioxin-like 
toxicity of carbazole and chlorocarbazoles in soil. Environ Sci Pollut Res 22:1344-1356

Nam I-H, Kim Y-M, Murugesan K, Chang Y-S (2012) A aatabolic activity of Sphingomonas wittichii RW1 in the biotransformation of carbazole. Water Air Soil Pollut 223:943-949

Nebert DW, Dalton TP (2006) The role of cytochrome P450 enzymes in endogenous signaling pathways and environmental carcinogenesis. Nat Rev Cancer 6:947-960

Ouchiyama N, Zhang Y, Omori T, Kodama T (1993) Biodegradation of Carbazole by Pseudomonas spp. CA06 and CA1O, Biosci. Biotech Biochem 57(3):455-460

Parshikov IA, Netrusov AI, Sutherland JB (2012) Microbial transformation of azarenes and potential uses in pharmaceutical synthesis. Appl Microbiol Biotechnol 95:871-889

Peddinghaus S, Brinkmann M, Bluhm K, Sagner A, Hinger G, Braunbeck T, Eisentrager A, Tiehm A, Hollert H, Keiter SH (2012) Quantitative assessment of the embryotoxic potential of NSO-heterocyclic compounds using zebrafish (Danio rerio). Reprod Toxicol 33:224-232

Seo J-S, Keum Y-S, Cho IK, Li QX (2006) Degradation of dibenzothiophene and carbazole by Arthrobacter sp. p 1-1. Int Biodeterioration Biodegrad 58:36-43

Singh GB, Gupta S, Srivastava S, Gupta N (2011a) Biodegradation of carbazole by newly isolated Acinetobacter spp. Bull Environ Contam Toxicol 87:522-526

Singh GB, Srivastava S, Gupta S, Gupta N (2011b) Evaluation of carbazole degradation by Enterobacter sp. isolated from hydrocarbon contaminated soil. Recent Res Sci Tech 3(11):44-48

Słaba M, Szewczyk R, Piątek MA, Długoński J (2013) Alachlor oxidation by the filamentous fungus Paecilomyces marquandii. J Hazard Mater 15:443-50

Sverdrup LE, Krogh PH, Nielsen T, Kjćr C, Stenersen J (2003) Toxicity of eight polycyclic aromatic compounds to red clover (Trifolium pratense), ryegrass (Lolium perenne), and mustard (Sinapsis alba). Chemosphere 53:993-1003

Testerink C, Munnik T (2005) Phosphatidic acid: a multifunctional stress signaling lipid in plants. TRENDS Plant Sci 10(8):368-375

The Agency for Toxic Substances and Disease Registry http://www.atsdr. cdc.gov/spl/ Accessed 08 April 2015

The European Trade Union Institute (2009) http://risctox.istas.net/en/dn risctox_ficha_sustancia.asp?id_sustancia $=961982$ Accessed 08 April 2015

Welti R, Li W, Li M, Sang Y, Biesiada H, Zhou H-E, Rajashekar CB, Williams TD, Wang X (2002) Profiling membrane lipids in plant stress responses. Role of phospholipase D in freezing-induced lipid changes in Arabidopsis. J Biol Chem 277:31994-32002

Xia J-M, Yuan Y-J (2009) Comparative lipidomics of four strains of Saccharomyces cerevisiae reveals different responses to furfural, phenol, and acetic Acid. J Agric Food Chem 57:99-108

Xu P, Yu B, Li FL, Cai XF, Ma CQ (2006) Microbial degradation of sulfur, nitrogen and oxygen heterocycles. TRENDS Microbiol 14(9):398-404

Yang W, Davis PJ (1992) Microbial models of mammalian metabolism. Biotransformations of N-methylcarbazole using the fungus Cunninghamella echinulata. Drug Matab Dispos 20:38-46

Yoon BJ, Lee DH, Kang YS, Oh DC, Kim SI, Oh KH, Kahng HY (2002) Evaluation of carbazole degradation by Pseudomonas rhodesiae strain KK1 isolated from soil contaminated with coal tar. J Basic Microbiol 42(6):434-43

Zhang D, Yang Y, Leakey JEA, Cerniglia CE (1996) Phase I and phase II enzymes produced by Cunninghamella: elegans for the metabolism of xenobiotics. FEMS Microbiol Lett 138(2-3):221-6

Zhao C, Zhang Y, Li X, Wen D, Tang X (2011) Biodegradation of carbazole by the seven Pseudomonas sp. strains and their denitrification potential. J Hazard Mater 190:253-259 